\title{
Intraocular Sustained-Release Delivery Systems for Triamcinolone Acetonide
}

\author{
Saffar Mansoor, ${ }^{1}$ Baruch D. Kuppermann, ${ }^{1}$ and M. Cristina Kenney ${ }^{1,2,3}$
}

Received August 12, 2008; accepted December 11, 2008; published online January 28, 2009

\begin{abstract}
Recently, the use of triamcinolone acetonide (TA) injection has increased dramatically in treatment for several ocular diseases. Among them, macular diseases such as macular edema due to diabetic retinopathy, venous occlusive diseases, ocular inflammation and age-related macular degeneration (AMD) are very common vision threatening disorders and are great challenges to treat. In these types of chronic retinal diseases, repeated intraocular injections of TA are often required which increases the likelihood of complications. In order to achieve sustained-release, maintain therapeutic levels of TA over longer times and reduce frequency of intravitreal injections, researchers are investigating different implantable devices or injectable systems. However, as of yet, there is no sustained-release product for TA available on the commercial market. This review discusses and compares different sustained-release devices or injectable systems that are currently being developed.
\end{abstract}

KEY WORDS: conjugates/codrugs; drug delivery system; microcannulation; ocular implants; triamcinolone.

\section{INTRODUCTION}

Triamcinolone acetonide (TA) is a synthetic corticosteroid structured as 9-fluoro-11b,16a,17,21-tetrahydroxypregna1,4-diene-3,20-dione cyclic 16,17-acetal with acetone. The empirical formula is $\mathrm{C}_{24} \mathrm{H}_{31} \mathrm{FO}_{6}$ and molecular weight is 434.50 (1). It has 7.5 -fold higher anti-inflammatory potency than cortisone $(2,3)$. Corticosteroids in general act through the induction of lipocortin synthesis. Arachadonic acid, a common precursor of prostaglandins and leukotrienes (effective mediators of inflammation), is released from membrane phospholipids by phospholipase A2. Lipocortins inhibit the phospholipase A2 (4,5). In addition to their anti-inflammatory action, corticosteroids exhibit vasoconstrictive (6), and anti-proliferative (7-9) effects. Corticosteroids can also inhibit angiogenic growth factors and choroidal neovascularization (growth of abnormal new blood vessels from the choroidal vasculature) in several animal studies (10). Moreover, corticosteroids stabilize the blood-retinal barrier (BRB) and are used to control macular edema in several retinal diseases $(11,12)$. The mechanism of macular edema begins with migration of leukocytes and vascular endothelial growth factor (VEGF) production $(13,14)$. The leukocytes adhesion

Supported by the Discovery Eye Foundation, Henry L. Guenther Foundation, Iris and B. Gerald Cantor Foundation and the Research to Prevent Blindness Foundation.

\footnotetext{
${ }^{1}$ Department of Ophthalmology, School of Medicine, University of California Irvine, Irvine, California, USA.

${ }^{2}$ Department of Ophthalmology, University of California Irvine, Medical Center, 101 The City Drive, Building 55, Rm 220, Orange, California 92868, USA.

${ }^{3}$ To whom correspondence should be addressed. (e-mail: mkenney@ uci.edu)
}

to endothelium disrupts tight junctions (15), which in turn increases breakdown of BRB and vascular permeability, causing edema (16). The corticosteroids can increase tight junction integrity which protect the blood-ocular barrier and decrease leakage $(11,17)$. It has also been demonstrated that corticosteroids have an antiapoptotic effect (18) and can protect the retinal photoreceptors via activation of glucocorticoid receptors. The eye possesses unique challenges with respect to drug delivery especially with respect to the posterior segment (choroid, retina, and vitreous) and treating vision threatening diseases. TA is one of the most extensively used drugs in the treatment of several ocular diseases which are characterized by inflammation, edema and neovascularization. However, while the drug is effective, the drug delivery system is not ideal and many side effects and complications can occur. Novel and more efficient delivery systems are being sought. To understand the current and new approaches for delivery of drugs to the posterior segment, a closer look at the structure as well as anatomic and physiologic barriers of the eye is necessary.

\section{Structure of the Eye}

The wall of the eye contains three major concentric layers (the outer, middle, and inner layers) and two fluid chambers (aqueous and vitreous humor). Other key elements of the eye include the cornea, pupil, lens, retina, macula, and optic nerve. Fig. 1 shows the general anatomy of the human eye. The sclera and cornea make up the outermost layer. The sclera is composed of tough connective tissues with an overlying thin, transparent membrane called the conjunctiva. The cornea is a transparent dome-shaped window that allows light to enter the eye. It is major refractive part of the eye, is avascular and nourished by the aqueous humor and 


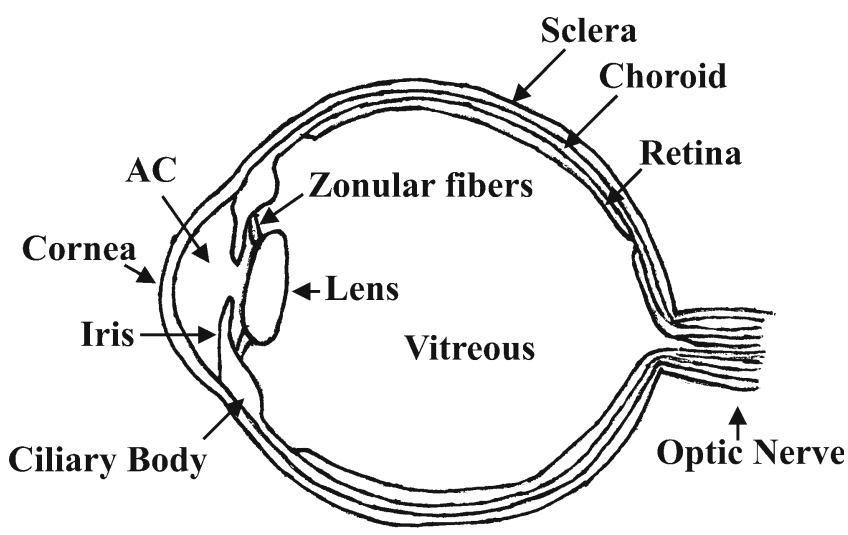

Fig. 1. Schematic of the structure of the human eye. $A C$ anterior chamber.

peripheral vessels. The middle layer consists of iris, ciliary body, and choroid. The choroid is a vascular network which supplies oxygen and nutrients to the outer half of the retina. The opening of the iris is called the pupil which constricts or dilates through the action of sphincter or dilator muscles in response to light. At the iris base is a specialized region called the ciliary body which produces the aqueous humor that provides nutrients for the anterior segment. The lens also provides refractive power and accommodation. The posterior segment is filled with a jelly-like substance called vitreous humor. The inner layer is the retina and has a function similar to the film in a camera. The retina can be divided into two regions: retinal pigmented epithelium (RPE) and neural retina. RPE is firmly attached to the Bruch's membrane which is adjacent to the choroid. The neural retina contains millions of photoreceptors of which there are two types: rods and cones. Rods are mainly responsible for peripheral and night vision. Cones provide color and detailed vision. A small region with a high concentration of cone photoreceptors is called the macula which provides fine details for reading and sharp vision. Each photoreceptor connects by nerve fibers to form the optic nerve. The retina has ten layers that contain numerous, different cell types that function to capture light rays and convert them into electrical impulses that travel along the optic nerve to the brain where they are processed into images.

\section{Barriers in Ocular Drug Delivery}

Ocular diseases in the anterior segment (cornea, conjunctiva, sclera, and anterior uvea) can be treated with conventional dosage forms such as eye drops, suspensions and ointments. However, some diseases of the posterior segment can not be treated with conventional drugs mentioned above (19). The reason is that topically applied drugs are washed away by lacrimation; tear dilution and tear turnover. The cornea, aqueous humor, and crystalline lens create resistance to drug entry into the posterior segment (20).The blood-aqueous and BRB further restrict the entry of systemically or orally administered drugs into the posterior segment. The blood-aqueous barrier is composed of the endothelial cells in the uvea (consisting collectively of the iris, choroid, and ciliary body). BRB can be classified into an inner and outer BRB. Outer BRB is created by tight junctions of the RPE cells that prevent the entry of even small molecules into retina from the choroid. The RPE cells possess various mechanisms such as transporters and efflux pumps that prevent penetration of substances but allow selective passage of nutrient from the choroid into the vitreous (21-23). The inner BRB is due to the retinal vessel endothelial cells that cause blockage of the systemic penetration of drugs. Because of such barriers, systemically or orally administered drugs are found in non-therapeutic levels and do not target the pathological conditions of the retina. In order to achieve therapeutic levels, systemic or oral routes require large doses of drugs but this often causes significant systemic side effects (24).Therefore, direct intraocular injec-

Table I. Uses of Triamcinolone Acetonide in Therapeutics

\begin{tabular}{ll}
\hline Therapeutics (references) & Methods of injection \\
\hline Extraocular/periocular diseases & Intralesional \\
Chalazion (96) & Subconjunctival \\
Scleritis (97) & Sub-tenon/transtenon, retrobulbar \\
Uveitis (98) & Supratarsal \\
Vernal keratoconjunctivitis (99) & Periocular/Intraorbital \\
Thyroid-associated ophthalmopathy (100) & Intravitreal \\
Intraocular diseases & Intravitreal \\
Refractory cystoid macular edema (101) & Intravitreal \\
Diabetic macular edema(102) & Intravitreal \\
Macular edema associated with central retinal vein occlusion (103, 104) & Intravitreal \\
Exudative macular degeneration (105) & Intravitreal \\
Combined photodynamic therapy/TA for exudative macular degeneration (39) & Sub-tenon \\
Idiopathic juxtafoveal telangiectasia (106) & Intravitreal \\
Choroidal neovascularization (CNV) associated with presumed ocular & Mid-vitreous cavity \\
histoplasmosis syndrome (POHS) (107) & Injection \\
Serous retinal detachment with Vogt-Koyanagi-Harada syndrome (VKH) (108) & \\
Surgical uses & \\
Triamcinolone acetonide assisted pars plana vitrectomy (109) & \\
Triamcinolone acetonide assisted anterior vitrectomy (110) & \\
\hline
\end{tabular}


tion delivers the desired amount of drug and minimizes extraocular side effects $(25,26)$.

\section{Triamcinonlone Acetonide in Ocular Therapy}

TA is a water insoluble drug, can remain for a longer duration in the vitreous cavity and may have longer action following intravitreal administration compared to other steroids that disappear with a few days (27). Moreover, TA has been considered a comparatively safe and effective drug in treatment of ocular diseases such as uveitis, macular edema secondary to retinal vascular disease, and neovascularization i.e., $\mathrm{CNV}$ in age-related macular degeneration (AMD) and vitreoretinopathy (28). Many of these disorders require long term steroid administration. The TA used in ophthalmology is available as an injectable suspension. Some brands of TA are Tricinolon, Tramacin, Flutex, Kenacort-A, Ledercort D, Oncilon-A, Respicort, Rineton, Solodelf, Kenaquart, Vetalog, Volonimat, Aristocort Acetonide and Kenalog. The most commonly used TA is Kenalog-40 (40 mg/mL, Bristol-MyersSquibb, Peapack, NJ, USA). Trivaris $(80 \mathrm{mg} / \mathrm{mL}$, Allergan, Inc. USA) and Triesence (40 mg/mL, Alcon, Inc. USA) are recently FDA approved brands of TA for ophthalmic use. In the past few years, use of TA has increased dramatically in treatment for several ocular diseases and as a surgical aide in vitreous/ocular therapies (Table I). This is also supported by observing a drastic rise (13-fold) in the number of PubMed citation, using a Kenalog-Intravitreal search, from 2002 to 2005 (29). Fig. 2 shows the location of ocular injections.

Macular edema that is associated with diabetic retinopathy, venous occlusive diseases, ocular inflammation, and AMD are very common vision threatening diseases and presents a significant challenge in regards to treatment. Patient with type-II diabetes mellitus are at risk of developing diabetic macular edema (DME). Patients with a 10-year history of diabetes have a $7-10 \%$ incidence of DME. At 20 years, its incidence increases to $25-30 \%$.In the presence of proliferative diabetic retinopathy (PDR), there is a $71 \%$ incidence of DME (19). DME is characterized by swelling of the macula due to gradual leakage of fluids from blood vessels and breakdown of the blood-retinal barrier (30). In addition to diabetes mellitus, hypertension can cause an increase in hydrostatic pressure within blood capillaries resulting in leakage of fluid into the surrounding retina. DME is of two types: focal or non-cystoid DME and diffuse or cystoid DME. Focal edema is associated with deposition of exudates (lipoprotein) resulting from microaneurysms leakage. Diffuse edema represents more extensive breakdown of the blood-retinal barrier, with the leakage from both microaneurysms and retinal capillaries (31, 32). Clinically optical coherence tomography (OCT) is used to

\section{Location of Ocular Injections}

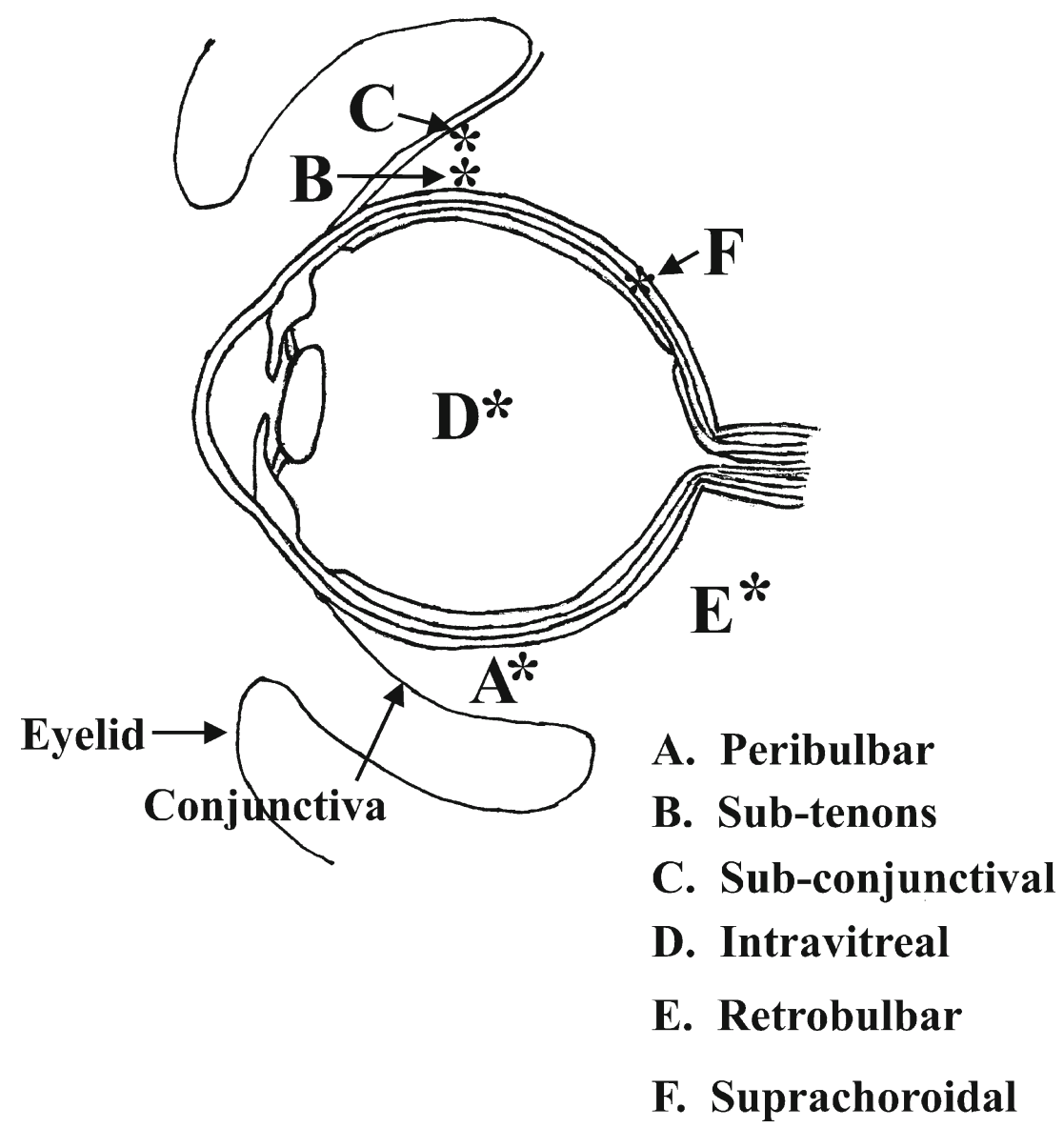

Fig. 2. Schematic showing the location of different ocular injections. 
diagnose and evaluate therapeutic response following treatment for DME (33). OCT is a noninvasive, non-contact, imaging device used to obtain high resolution cross-sectional images of the retina that allows the eye care professional to differentiate normal retina from DME. Fig. 3 shows an image of a retina with DME that has an accumulation of fluid resulting in increased retinal thickness. The DME can be treated with intravitreal injections of TA (IVTA) alone or in combination with anti-VEGF medications. Due to complexity of the responses from such vision threatening diseases, therapies that target more than one component of the pathological condition may show clinical benefit over single therapy. VEGF is the major angiogenic stimulus for neovascularization but also there is a strong immunologic role in angiogenesis (34). Therefore, antiVEGF treatment can antagonize neovascularization, reduce or stop vessel leakage, and alleviate edema where as IVTA can act by its broad range of action discussed earlier. So the treatment that allows interfering of both pathways would be more efficient over monotherapy that only blocks one of the pathways.

AMD has affected nearly 15-20 million people and is the most common cause of blindness in patients over 65 years of age (35). There are two types of AMD (Fig. 4): dry AMD (nonexudative/atrophic), and wet AMD (exudative/neovascular). Age is one of the major risk factors for AMD. Other risk factors are race, cardiovascular diseases, smoking and AMD in the contralateral (fellow) eye. Initially, the disease begins with formation of small-sized drusen (yellow lipofuscin deposits) underneath the retina. Dry AMD is found in $85-90 \%$ of AMD subjects. It is characterized by a slow breakdown of photoreceptors, and retinal pigment epithelium (RPE) leading to vision loss. In wet AMD, there is CNV which are fragile causing leakage of blood and fluid into the subretinal space and subsequent scar formation. Other characteristics of AMD include disruption of Bruch's membrane and degeneration of RPE, both of which can contribute to decreased visual acuity (36-38). The CNV can be treated by a combination therapy of IVTA and photodynamic therapy (PDT) which acts synergistically to improve the vision and reduces the number of treatments required to maintain acuity (39-44). PDT produces oxidative radicals that cause selective toxicity for neovascularization and also affects physiology of the choroidal vasculature (45). Following PDT treatment, there is a transient thrombotic occlusion of adjacent choriocapillaries and increased expression of VEGF with induction of various inflammatory mediators (46). IVTA leads to a transient reduction in leakage from CNV, and inhibits VEGF expression and inflammatory pathways (47). Most recently anti-VEGF medications have been used to treat the wet form of AMD.

The response and side effects to TA vary greatly because individual patients can responded differently to the same doses of TA. With recent clinical and experimental studies confirming the pivotal role of IVTA in the successful management of several vision affecting diseases mentioned earlier, the use of IVTA has increased by several folds in the past 5 years (29). However, the prolonged effects and ultimately successful therapy depends on the retention of IVTA. The longer retention, the longer the drug half-life. There are a number of papers showing that a great difference in the TA half-life in the vitreous depending on frequency of injection, concentration of drug, animal species, and the condition of the eye (vitrectomized

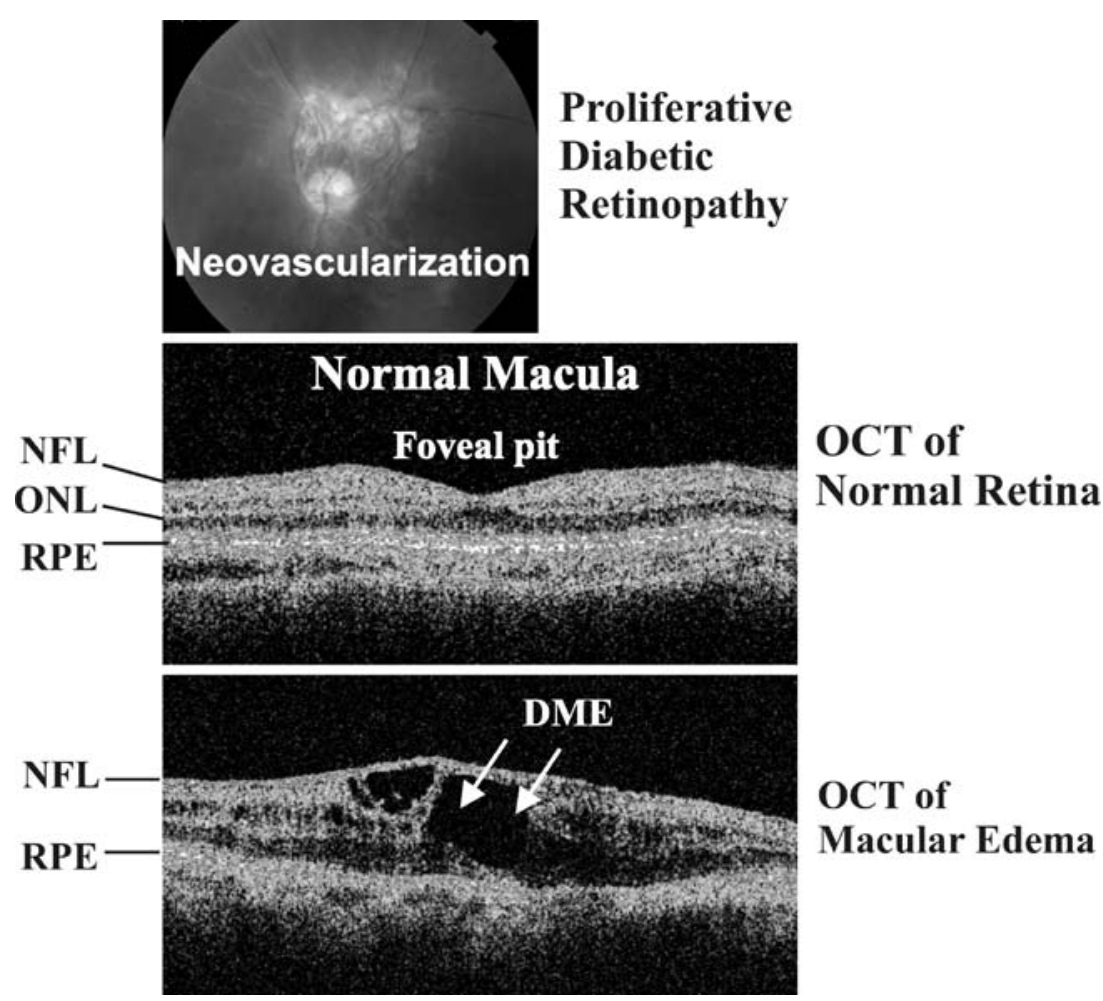

Fig. 3. Retinal images of proliferative diabetic retinopathy. The OCT demonstrates a normal retina and a retina with macular edema. The fovea is the region of high concentration of cone photoreceptors and appears as a depression within the retina. When DME occurs then intraretinal fluid causes thickening and the foveal pit disappears. RPE retinal pigment epithelial cells, $O N L$ outer nuclear layer, $N F L$ nerve fiber layer. 
Normal Retina

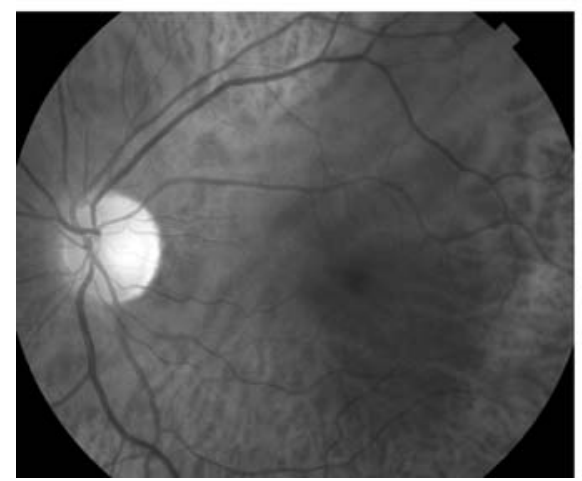

Dry AMD

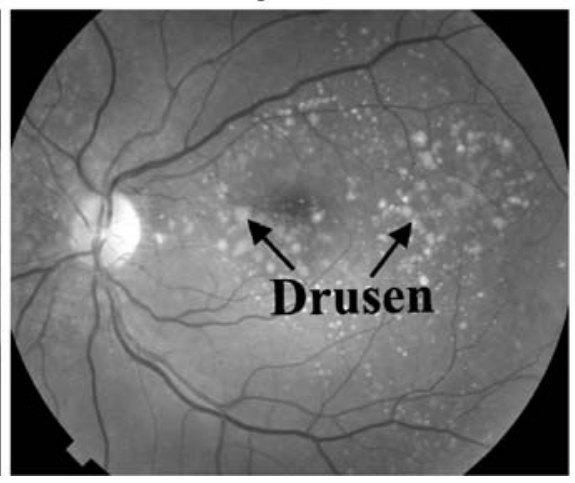

Wet AMD

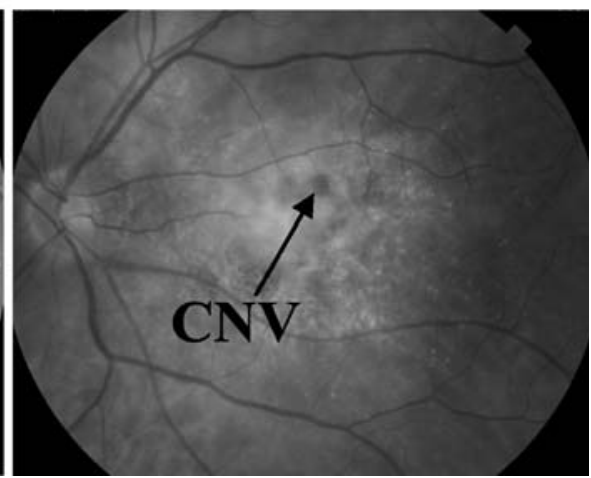

Fig. 4. Images of the retinal fundus from a normal eye, an eye with dry AMD and wet AMD. Note the numerous drusen in the dry AMD fundus. The wet AMD shows a region of choroidal neovascularization $(C N V)$ that can lead to subretinal scarring and loss of vision.

versus nonvitrectomized)(27,48,49). The intravitreally injected drug is rapidly eliminated by the eye's natural circulatory process so that frequent injections may be required which are unpopular with many patients. Therefore, large dose injections are often required to be effective (50) but are associated with several ocular complications/side effects including increased intraocular pressure (IOP), cataract formation, endophthalmitis, pseudoendophthalmitis and increased risk of retinal detachment (28).

Presently, investigations are underway to test the feasibility of introducing TA directly into the subretinal space using implantable devices or by injecting suspensions or microspheres of TA that will allow sustained-release of the drug. Alternatively, another approach for the injectable system includes a novel technique of direct injection of TA into the suprachoroidal space (SCS) in which therapeutic levels of TA can be maintained for longer durations. If successful, the need for frequent use of conventional injections would be reduced and the procedure would be an option for treatment of several vision threatening diseases. This review focuses on the work that has been conducted for the controlled-release of TA with emphasis on preparation of the devices, polymers used, in vitro/ in vivo performance, strengths, and weakness for each device or injectable system (Table II).

\section{INTRAOCULAR SUSTAINED-RELEASE DELIVERY SYSTEM}

Currently, administration of TA for different ocular therapies is made by direct intravitreal injection. Various researchers have studied different implantable devices or injectable systems, many of which ultimately showed sustained-release performance of TA. However, as of yet, there is no sustained-release product for TA available on the market although one device developed by Surmodics Inc. (Eden Prairie, MN), is in phase I clinical trial (51). Beside TA implants, pharmaceutical companies have developed intraocular implants using steroids other than TA as the active ingredients or using some other drug or encapsulated cells to treat vitreoretinal diseases (Table III). Some examples are:

1. Posurdex (Allergan Inc., USA) uses dexamethasone (with dose of $700 \mu \mathrm{g}$ ) and is a biodegradable, micro-sized implant which would release drug over a month. It is in phase III clinical trials for the treatment of macular edema due to retinal vein occlusion, DME, and uveitis (52).
2. Surodex (Allergan Inc., USA) uses dexamethasone (with dose of $60 \mu \mathrm{g}$ ) and is a biodegradable, microsized implant which show release performance of drug for 7 days. It is in Phase III clinical trials for the treatment of postoperative inflammation following filtering surgery on eyes with glaucoma $(53,54)$.

3. Retisert (Bausch \& Lomb, Rochester, USA) has fluocinolone acetonide as the active ingredient. This implant is disc-shaped $(3 \times 2 \times 5 \mathrm{~mm})$ and can release the drug up to 3 years. This implant is approved by FDA for the treatment of chronic noninfectious uveitis affecting the posterior segment (55).

4. Medidur (Alimera Sciences, USA and pSivida Inc., USA) is a tiny rod-shaped (length $3.5 \mathrm{~mm}$, diameter 0.37) implant containing fluocinolone acetonide with drug release duration of $18-36$ months. It is in the Phase III FAME (Fluocinolone Acetonide in Diabetic Macular Edema) trial (http://www.alimerasciences. com/medidur_overview.asp).

5. Vitrasert (Bausch \& Lomb, Rochester, USA) is the first implantable millimeter-sized device for ganciclovir (an anti-viral drug) and can release the drug for 8 months. This implant is approved by the FDA to treat patients with AIDS-related cytomegalovirus (CMV) Retinitis (56).

6. NT-501 (Neurotech Inc., USA) is genetically engineered RPE cells contained within encapsulated cell technology (ECT). Following implantation, there is secretion and controlled delivery of ciliary neurotrophic factor (CNTF) to the back of the eye. The release duration of $\mathrm{CNTF}$ is 18 months and can be used for glaucoma, CNV, and uveitis. It is in Phase II clinical trials $(57,58)$.

The following is a brief discussion about implantable devices/injectable systems for TA:

\section{Implantable Devices}

Almost all implants are made of polymers and can be classified into either biodegradable or nonbiodegradable devices. Biodegradable polymers are gradually converted into a soluble form through enzymatic or non-enzymatic reactions in the body. The nonbiodegradable polymers are not metabolized or degraded and therefore, once empty must 


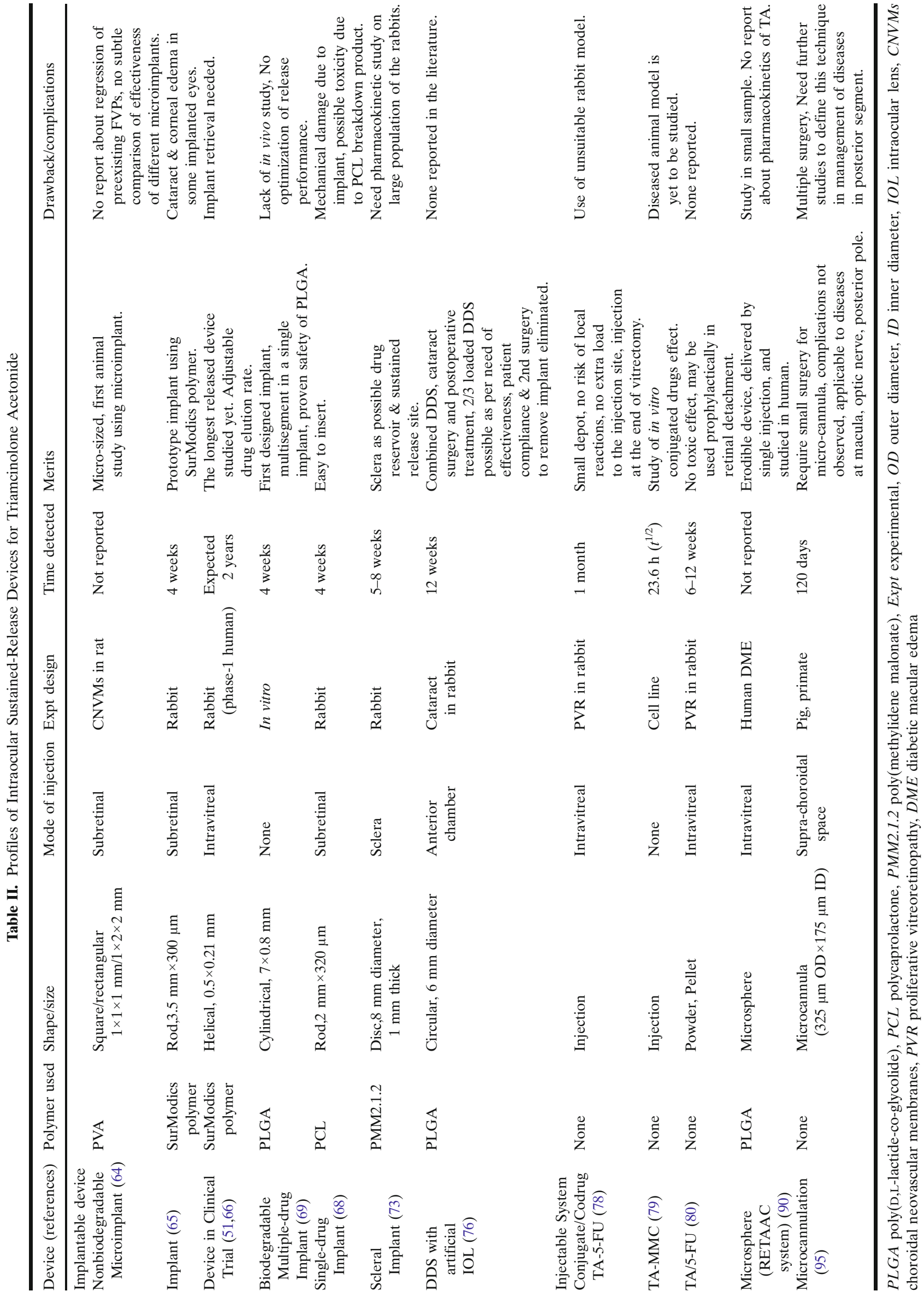


be removed by a second surgery which exposes the patient to potential complications (59). This is an advantage for the biodegradable devices in that further invasive procedures for their retrieval are eliminated. Both biodegradable and nonbiodegradable materials have been designed into various forms. There are implantable devices that are shaped as flat sheets, pellets, discs, rods, or plugs. In addition, the intravitreal injectable systems are found in the forms of suspensions and microspheres (60) or as a new technique that injects the drug into the SCS. Fig. 5 summarizes the different sustained-release implantable (nonbiodegradable, biodegradable) devices for TA studied to date.

\section{Nonbiodegradable Devices}

The polymers used for nonbiodegradable devices of TA sustained-release are polyvinyl alcohol (PVA) and ethylene vinyl acetate (EVA). PVA is a permeable polymer that provides the framework to regulate the rate of drug permeation. EVA is an impermeable polymer that restricts the device surface area through which the drug can be released (61). The mechanism of drug release is that fluid diffuses into the device and dissolves the drug pellet into a saturated solution which is then released by diffusion into the surrounding area, while the inside solution remains saturated with drug, making release rate constant (62). The nonbiodegradable polymeric devices lack an initial burst of drug, and controlled-release can be achieved for many years. Moreover, the distribution is localized so that higher drug concentrations are found in the vitreous compared to the aqueous humor with the serum concentrations being the lowest (63). There have been two recent studies for novel nonbiodegradable devices to release TA, the microimplant and the implant.

Microimplant. Ciulla et al. (64) demonstrated that various TA concentrations could be delivered effectively for a longer duration from intravitreal microimplants, (square/rectangular $1 \times 1 \times 1 / 1 \times 1 \times 2 \mathrm{~mm}$ sheets) prepared using PVA polymer matrices. An in vitro study showed 22-35 days of TA release from these sheets. However, in vivo measurement of vitreous concentrations of TA in the rat was not feasible because of the small volume of the eye. To study in vivo therapeutic effects, the TA microimplants were inserted (subretinal) into the rat's eyes following induction of choroidal neovascular membranes (CNVMs) by laser treatment. In vivo evaluations were measurement of the thickness of fibrovascular membranes at various intervals. These implants inhibited fibrovascular proliferation (FVP) disease for at least 35 days. It is the first animal study using microsize TA implants. However, this study was designed to evaluate inhibition of FVPs, but not regression of preexisting FVPs, which more accurately reflects the actual human CNVM condition. In this model, the rapidly developed FVP also prevented comparisons of any subtle difference in effectiveness between various microimplant designs with each other. Importantly, there were no complications following microimplant insertion mentioned in the literature.

Implant. Beeley et al. (65) studied in rabbits another novel implantable device that is a biocompatible, sustained release, subretinal drug delivery implant for TA. This rodshaped implant consists of a $3.5 \mathrm{~mm}$ long filament $(300 \mu \mathrm{m}$ 


\section{A. Nonbiodegradable Devices}

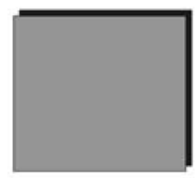

\section{Square Microimplant} $1 \times 1 \mathrm{~mm}$

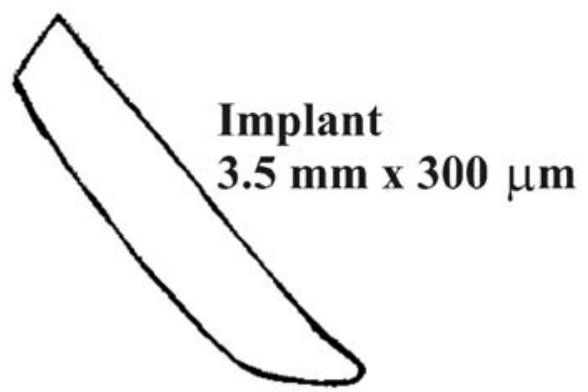

\section{B. Biodegradable Devices}

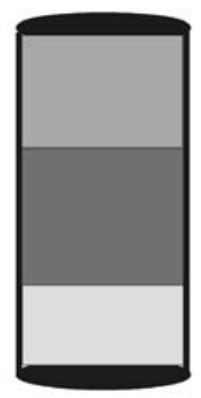

\section{Cylindrical Microimplant $0.8 \times 7 \mathrm{~mm}$}

\section{Rectangular Microimplant} $1 \times 2 \mathrm{~mm}$

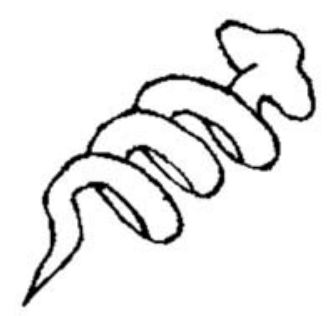

I-vation Implant $0.5 \times 0.21 \mathrm{~mm}$

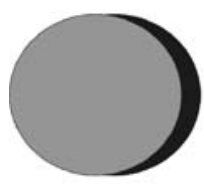

\section{Scleral Implant $8 \mathrm{~mm}$ diameter $1 \mathrm{~mm}$ thickness}

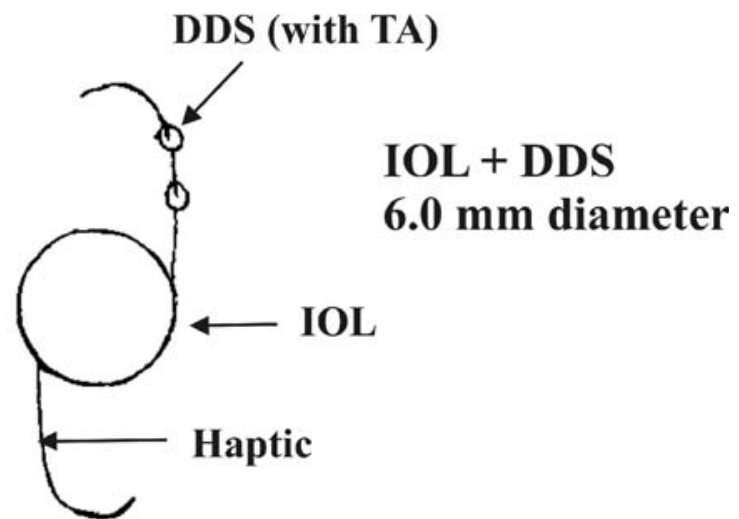

Fig. 5. Schematic of intraocular implantable devices. a Nonbiodegradable devices. b Biodegradable devices.

diameter) with an outer drug-loaded polymer coating. The inner filament is an etched nitinol core wire that is loaded with TA mixed with poly(methyl methacrylate) (PMMA) and poly(ethylene-covinyl acetate). Coating of the TA with PMMA and poly (ethylene-covinyl acetate) polymers has been manufactured by SurModics, Inc. This type of coating technology is being used currently in sirolimus-eluting cardiovascular stents in human patients. As an in vivo study, implants were surgically inserted into the subretinal space of $20 / 24$ rabbits. The implants were evaluated on the basis of clinical tolerability (assessed by examination) and levels of in vivo drug elution. It was a preliminary study using the prototype implant and coating technology by SurModics polymer. The implants were found to be well tolerated and could elute TA for 4 weeks. However, during a 4 weeks follow-up period, although good retinal tolerance was observed, cataract and corneal edema developed in six implanted eyes.

Devices in Clinical Trial. SurModics Inc. has a delivery system using I-vation technology capable of delivering TA on a sustained-release basis. There are two I-vation TA for- 
mulations: slow- release $(\sim 1 \mu \mathrm{g}$ per day), and fast-release form ( $\sim 3 \mu \mathrm{g}$ per day). In the I-vation intravitral implant, there is a helical coil coated with TA and polymer. The polymers are PMMA and poly (ethylene-covinyl acetate) similar to the previously discussed implant. The advantages of this implant are the unique helical design (approximate length of $0.5 \mathrm{~mm}$ and width of $0.21 \mathrm{~mm}$ ) that maximizes the surface area available for drug delivery, ensures secure anchoring of the implant at the scleral wall and facilitates ease of its retrieval. It is predicted that this implant will have an in vivo sustained delivery for a minimum of 2 years. Safety and biocompatibility of this implant have been studied extensively in a preclinical rabbit model. The implants were placed in more than 100 rabbit eyes and followed clinically for 9 months postimplantation. Results showed that implants were well tolerated, with no observed retinal toxicity and very little fibrous encapsulation of the implant. Removal of the implant was straightforward involving a small incision through which the implant could be extracted. Presently, I-vation is in Phase 1 human clinical trials in patients with DME. This is the device with the longest release history studied yet. If successful, Ivation could replace the need for multiple intravitreal injections and would be a major arsenal to treat both diabetic retinopathy and AMD (51,66). However, implant retrieval would be needed in all cases.

The nonbiodegradable implants are a popular choice for sustained-release ophthalmic drug delivery because they offer adjustable drug release profiles and have a proven clinical efficacy. However, these nonbiodegradable implants are not the only choice available since there is rapidly advancing technologies in other polymeric systems such as biodegradable implants and microspheres.

\section{Biodegradable Devices}

Devices for intraocular sustained-release of TA have been studied using limited biodegradable polymers. The most popular polymers include poly(lactic acid) (PLA), poly (glycolic acid) (PGA), and their copolymer, poly(lactic-coglycolic acid) (PLGA). Some implants also use polycaprolactones (PCL) and poly(methylidene malonate) (PMM2.1.2) polymers. In general, the biodegradable polymers degrade through enzymatic and nonenzymatic hydrolysis of polymeric chains $(67,68)$ and as a result, sustained drug release is achieved. Importantly, the release rates can be manipulated. However, the release performance (of drugs) is shorter as compared to nonbiodegradables devices.

Multiple-Drug Implant. Sustained delivery of multiple drugs from a single implant has also been investigated. Zhou et al. (69) fabricated a multiple-drug delivery system to treat proliferative vitreoretinopathy (PVR). For this implant, PLGA was chosen as the matrix material. In the last two decades, PLGA has been found to have well-proven biocompatibility, biodegradability (70) and manipulatable releaserate and has received FDA approval as an implantable material (71). Furthermore, the PLGA degradation products, lactic and glycolic acids are metabolized through the Krebs cycle to carbon dioxide and water. These physical properties have made PLGA highly attractive for the controlled delivery of drugs (72). The cylindrical implant (7 mm long and $0.8 \mathrm{~mm}$ diameter) had three parts containing 5-fluorouridine (5FUrd), TA, and tissue plasminogen activator (t-PA). This implant released 5FUrd and TA over 4 weeks and the t-PA over 2 weeks. It was the first designed and studied device with multisegment (for different types of drug) in a single implant. The multisegment design, unlike conjugates allows independent release of individual drugs without affecting the release rate of the other drugs. However, while this regimen approach has undergone a preliminary in vitro controlled-release study for the management of PVR, the system needs in vivo evaluation and optimization of the release performance.

Single-Drug Implant. In another study, Beeley et al. (68) evaluated an implant made of PCL polymer for delivery of TA. PCL degrades over a longer period than PLGA which would allow for a longer duration delivery. The rod-shaped implant ( $2 \mathrm{~mm}$ in length and $320 \mu \mathrm{m}$ in diameter) was made by embedding the TA within PCL at different polymer/drug ratios. In vitro analysis demonstrated 1 month elution capabilities of TA from the implant. For the in vivo study, the implants were surgically placed into the subretinal space of six rabbits and observed for drug release and complications for 4 weeks. The TA was released for 4 weeks and no complications were observed during the 4 weeks follow-up period. Histologically, there were no signs of inflammation due to the presence of the PCL polymer, thereby demonstrating its excellent biocompatibility with retinal tissues. The tissue TA drug levels were localized to the posterior eye segment and not detected in the anterior ocular structures or blood. However, the insertion of the implant although not difficult caused mechanical damage to the cellular layers. In addition, the possibility of retinal toxicity from the PCL breakdown products needs further long-term evaluation.

Scleral Implants. Felt-Baeyens et al. (73) developed ocular scleral implants to study sustained release of TA. Disc-shaped implants $8 \mathrm{~mm}$ in diameter with thickness of $1 \mathrm{~mm}$ were manufactured using PMM2.1.2 which is a relatively new synthetic polymer. The advantage of PMM2.1.2 as an implant is that it breaks down into nontoxic ethanol and glycolic acid (74,75). Following implantation into rabbit eyes, the scleral implants showed good ocular biocompatibility. The numbers of inflammatory cells and protein content in aqueous humor were low, indicating that these implants were well tolerated. The in vivo therapeutic concentrations of TA were found in the vitreous for 5 weeks and detectable levels were present for up to 8 weeks, thereby demonstrating sustained release of TA. Moreover, high concentrations (up to $500 \mathrm{ng} / \mathrm{mg}$ of tissue) of TA were found in the sclera, confirming it as the drug reservoir and sustained-release site. In conclusion, this study showed the scleral route as a potential reservoir for drugs used for the treatment of the posterior segment diseases, thus minimizing side effects associated with the systemic route. However, these results need to be confirmed by complete pharmacokinetic studies following implantation on a larger population of rabbits.

Drug Delivery System Associated with Artificial Lens. Very recently, an extended release device of TA and its efficacy with respect to reduction of post-operative inflammation in a rabbit 
model has been reported. Eperon et al. (76) developed a TA loaded biodegradable drug delivery system (DDS) combined with an artificial intraocular lens (IOL, $6.0 \mathrm{~mm}$ in diameter) called IOL+DDS. DDS loaded TA was produced as a disc $2 \mathrm{~mm}$ in diameter using PLGA with different molecular weights. The higher the molecular weight of PLGA, the slower was the release of TA from discs in vitro. For placement into eyes, one to three discs were threaded onto an IOL haptic. Cataract surgery was then performed on the rabbits eyes and an IOL with one, or two/three discs (IOL+1, 2/3 DDS with TA load) tied along the haptic was inserted. Using two DDS per IOL, the in vivo TA release was for 12 weeks. The protein concentration and inflammatory cell levels within aqueous humor showed that IOL+DDS was biocompatible and tolerated. One loaded DDS significantly reduced postoperative ocular inflammation. Two/ three loaded DDS effectively inhibited inflammation up to 84 days. No complications were reported in this study. An advantage of the IOL+DDS is that it combines cataract surgery and postoperative treatment in a single procedure. Another advantage is its release of low drug concentrations that are effective and have few side effects (77). Moreover, patient noncompliance as well as the need for a second surgery to remove the implant is eliminated. Therefore, IOL+DDS may be suitable for incorporation of other drugs (steroids, ganciclovir, antibiotics etc.) for treatment of the various sight threatening diseases. The technique may also be useful in AMD patients that face cataract surgery since some studies report a progression of AMD after cataract removal. Theoretically, the implant with either a steroid or anti-VEGF drug might decrease the likelihood of post-surgical AMD progression.

\section{Injectable System/Particles}

There are some preliminary studies to develop a technique of sustained-release TA using conjugate/codrug design. In conjugate/codrug systems, there is no use of polymers that can cause incompatibility and toxicity (78-80). In addition, the volume of injected conjugate/codrug can be small, so the concerns of polymeric load (81) to the eyes are eliminated. Also, this system does not include surgery, therefore is preferred by the patient (78-80). Using this system, TA is conjugated/combined with drugs such as 5fluorouracil (5-FU) or mitomycin C (MMC). The conjugates are designed by covalently linking two drugs whereas codrug are formed either by simple mixing or compressing two drugs together. The conjugate dissolves slowly and is hydrolyzed, giving sustained-release of TA.

Another development is the intraocular injection of microspheres to reduce the need for multiple intravitreal injections and/or surgical implantation of sustained-release devices. Microspheres provide a sustained-release injectable drug depot formulation that, in some cases, is able to target specific tissues. The microspheres range in size between 1 and $1,000 \mu \mathrm{m}$ in diameter and are made with either PLA or PLGA polymers (82-89).

Very recently, a novel injection method was developed that involves "microcannulation" into the suprachoroidal space (SCS) of the eye. The injected TA, delivered by microcannula, was retained for a longer period in the posterior segment of the eye.
The following briefly describes the intraocular injectable systems used for sustained-release/retention of TA:

\section{Conjugates/codrugs}

Berger et al. (78) reported a sustained drug delivery system of a TA and 5-FU conjugate that lacks any polymer component. The TA-5-FU conjugate (as a pellet) was injected intravitreally into the rabbit's eye following induction of proliferative vitreoretinopathy (PVR). There was sustainedrelease of TA and 5-FU for 1 month, which effectively inhibited the progression of PVR in this animal model. The conjugate system allowed for sustained-release of multiple drugs each of which can target different mechanisms of the disease and thereby improve healing efficiency. However, the rabbit model used in this study was not ideal for simulating the human condition because of the absence of vitrectomy and/or extended intraocular tamponade of gas or silicon oil in the model which is typically used after surgery for PVR in humans. It is unclear how the release rate of TA-5-FU conjugate would be impacted by these conditions.

Macky et al. (79) synthesized a TA and MMC (TAMMC) conjugate with a half-life of $23.6 \mathrm{~h}$ in aqueous solution. An in vitro study using this conjugate showed sufficient antiproliferative activities in a fibroblast cell line and its intravitreal injection into a rat eye model did not show any toxicity. However, the efficacy of TA-MMC conjugates in inhibiting proliferative diseases in animal/human eyes has yet to be studied. MMC is comparatively more toxic at higher concentrations; therefore, its release rate from any conjugate system must be manipulated to achieve the minimum vivo level needed for therapeutic effect.

Yang et al. (80) reported efficacy of an intravitreal sustained-release TA/5-FU codrug formulated as either an injectable powder for injection or a pellet for implantation for the treatment of an experimental PVR rabbit model. The codrugs of TA/5-FU powder and TA/5-FU pellet were prepared by direct compression of the powdered drug. For an in vivo study, the TA/5-FU powder was injected directly into the vitreous cavity where as the TA/5-FU pellet was implanted into vitreous cavity following PVR induction. Both the pellet and powder codrug systems showed sustainedrelease of TA and 5-FU and effectively inhibited progression of PVR in this rabbit model. The intact codrug in the vitreous cavity could be measured by 12 weeks and no drug-related toxic effects were found by either clinical or histopathologic examination. Future use of the codrug may include prophylactic injection at the time of primary scleral buckle to repair a rhegmatogenous retinal detachment, or following vitrectomy to repair a primary or recurrent rhegmatogenous retinal detachment in the presence or absence of PVR.

\section{Microspheres}

In general, microspheres are prepared by methods similar to preparing emulsions. That is, the first drug is suspended or dissolved in a non-aqueous (organic) solvent containing a polymer and is then mixed slowly with the aqueous solution containing surfactant. This mixing yields either an oil in water $(\mathrm{o} / \mathrm{w})$ or oil in oil $(\mathrm{o} / \mathrm{o})$ emulsion. Then the non-aqueous solvent is evaporated by heat or vacuum 
resulting in a suspension of solid microspheres loaded with the drug. Higher encapsulation efficiencies for hydrophilic drugs are obtained by o/o emulsion where as for lipophilic drugs the $\mathrm{o} / \mathrm{w}$ emulsion is preferable. Drug release from microspheres depends on several factors such as polymer composition and its molecular weight, drug hydrophilicity, drug loading, as well as microsphere size (60). Furthermore, the drug release rate from small microspheres is faster than larger ones (84).

Cardillo et al. (90) reported human studies of a controlled-release microsphere system for TA (referred in this study as the RETAAC system). RETAAC prepared with PLGA was injected intravitreally into patients with diffuse DME and their efficacy compared to direct TA-injections. Both the safety as well as the anatomic and functional outcomes was evaluated. RETAAC-treated eyes showed marked decrease of retinal thickness as well as improved visual acuity (VA) for 12 months. This study demonstrated a superior long-term pharmacologic performance compared to TA-injected eyes. RETAAC was found to be safe and well tolerated by the retina. The advantage of the RETAAC system is that they are erodible devices, can be delivered by use of simple injection and no scleral placement is required. No drug or procedure related side effects were observed in this study. Since, RETAAC is minimally invasive; it may be a feasible delivery system for sustained therapeutic quantities of TA to the retina. This would increase the duration of therapeutic effects compared to the conventional formulations and pellet systems. Therefore, RETAAC is a promising technique for the intraocular delivery of multiple drugs for the treatment of chronic posterior segment diseases. However, the disadvantage of this study is the small sample size (nine patients) and therefore additional investigations using large populations are necessary. Moreover, there was no report regarding pharmacokinetics of TA in this study.

\section{Microcannulation}

Intravitreal injections are reasonably well tolerated. However, limitations of intravitreal injections include the need for multiple injections, possible complications and the need for frequent follow-up visits to the physician. Also, more sustained delivery systems are needed for treatment of chronic eye diseases. Vitreous implants showed sustainedrelease performance of the drug but needed intraocular surgery for their placement (91-93). In addition, the devices are expensive and may need further surgical treatment for their removal or replacement (94). Olsen et al. (95) described a novel posterior drug delivery system (PDS) by means of microcannulation to SCS. Initially, cadaveric human eyes were studied and then the procedure was further optimized using two animal models; pigs and primates. The SCS is bound anteriorly by the scleral spur and posteriorly by the connections between the choroid and short posterior ciliary vessels. The microcannulation system takes into account the distinct anatomical boundaries of the SCS. The microcannula (325 $\mu \mathrm{m}$ outer diameter $\times 175 \mu \mathrm{m}$ inner diameter) used for this system is a flexible steel wire shaft and a fiber optic light source. To introduce the cannula, two parallel radial scleral incisions are used to expose the choroid and a second sclerotomy is made for the illuminated endoscope. A wide angle viewing system allows visualization by the surgeon. After placement of drug into the SCS, the scleral and conjunctival incisions are closed using 7-0 vicryl suture.

The TA retention was 120 days in the retina, choroid and vitreous with minimum elevation of systemic levels in either model. Histopathology demonstrated normal anatomy in uncomplicated cases. The advantages of this methodology are: (1) direct visualization of the cannula tip and the site of drug delivery, even through pigmented tissues; and (2) direct visualization of the drug bolus entering the SCS. In addition, this method may be applicable to a wide variety of pharmacotherapies for the macula, optic nerve, and posterior pole. But the limitations of this study are that microcannulation may not be feasible because it involves numerous surgical steps and manipulation. For example, it uses a steel wire shaft which can lead to mechanical damage, two scleral incisions and a sclerotomy that requires a suture after the placement of drug. All of these may be sources for potential complications for this methodology. Moreover, further clinical studies will be necessary to evaluate this technology for its potential in the management of posterior segment diseases.

\section{SUMMARY AND CONCLUSION}

The crucial need to limit the frequency of repeated intraocular injections for the treatment of AMD, DME or chronic intraocular inflammation has enhanced the need for the development of slow-release devices. As described in this review, most of the developed devices showed sustainedrelease of TA and induce marked therapeutic effects on experimentally induced eye diseases. However, polymer degradation in the implants may cause toxicity and the need for challenging surgical techniques has hampered the further development of these systems for routine clinical use. Therefore, additional studies to develop safe, innovative, efficient, sustained-release devices/system for TA should be pursued in order to provide novel therapies to treat chronic diseases of posterior segment of the eyes.

Open Access This article is distributed under the terms of the Creative Commons Attribution Noncommercial License which permits any noncommercial use, distribution, and reproduction in any medium, provided the original author(s) and source are credited.

\section{REFERENCES}

1. K. Kooner, T. Zimmerman, and M. Sharir. Textbook of ocular pharmacology. Lippincott-Raven, Philadelphia, 1997.

2. D. Argenti, B. K. Jensen, R. Hensel, K. Bordeaux, R. Schleimer, C. Bickel, and D. Heald. A mass balance study to evaluate the biotransformation and excretion of [14C]-triamcinolone acetonide following oral administration. J. Clin. Pharmacol. 40:770-780 (2000). doi:10.1177/00912700022009413.

3. K. Kreines, and I. C. Weinberg. The selection of adrenocorticosteroid preparations. Ohio State Med. J. 71:698 (1975). 703-706.

4. B. Jensen, D. Argenti, and R. Hensel. A mass balance study to evaluate the biotransformation and excretion of [14C]-triamcinolone acetonide following oral administration. J. Clin. Pharmacol. 40:770-780 (2000). doi:10.1177/00912700022009413. 
5. A. Boyd, I. G. Duguid, and T. E. Mandel. Adhesion molecules are expressed in the human retina and choroid. Curr. Eye Res. 11(Suppl):153-159 (1992).

6. J. Veraart, A. Sommer, and M. Neumann. Evaluation of the vasoconstrictive effects of topical steroids by laser-Dopplerperfusionimaging. Acta Derm.-Venereol. 78:15-18 (1998). doi:10.1080/ 00015559850135751.

7. R. A. Adler, S. A. Naumann, A. Mansouri, R. J. Krieg Jr., K. Latta, and K. M. Sanders. Anti-proliferative effects of deflazacort on $\mathrm{Nb} 2$ cells as quantitated by formazan production. Life Sci. 55:1823-831 (1994). doi:10.1016/0024-3205(94)90093-0.

8. J. B. Jonas, I. Kreissig, and R. Degenring. Intravitreal triamcinolone acetonide for treatment of intraocular proliferative, exudative, and neovascular diseases. Prog. Retin. Eye Res. 24:587-611 (2005). doi:10.1016/j.preteyeres.2005.01.004.

9. J. Sosnowski, C. Stetter-Neel, D. Cole, J. P. Durham, and M. G. Mawhinney. Protein kinase $\mathrm{C}$ mediated anti-proliferative glucocorticoid-sphinganine synergism in cultured Pollard III prostate tumor cells. J. Urol. 158:269-274 (1997). doi:10.1097/ 00005392-199707000-00084.

10. T. A. Ciulla, J. D. Walker, D. S. Fong, and M. H. Criswell. Corticosteroids in posterior segment disease: an update on new delivery systems and new indications. Curr. Opin. Ophthalmol. 15:211-220 (2004). doi:10.1097/01.icu.0000120711.35941.76.

11. E. A. Felinski, and D. A. Antonetti. Glucocorticoid regulation of endothelial cell tight junction gene expression: novel treatments for diabetic retinopathy. Curr. Eye Res. 30:949-957 (2005). doi:10.1080/02713680500263598

12. M. Nauck, G. Karakiulakis, A. P. Perruchoud, E. Papakonstantinou, and M. Roth. Corticosteroids inhibit the expression of the vascular endothelial growth factor gene in human vascular smooth muscle cells. Eur. J. Pharmacol. 341:309-315 (1998). doi:10.1016/S0014-2999 (97)01464-7.

13. H. E. Grossniklaus, J. X. Ling, T. M. Wallace, S. Dithmar, D. H. Lawson, C. Cohen, V. M. Elner, S. G. Elner, and P. Sternberg Jr. Macrophage and retinal pigment epithelium expression of angiogenic cytokines in choroidal neovascularization. Mol. Vis. 8:119-126 (2002).

14. J. McLaren, A. Prentice, D. S. Charnock-Jones, S. A. Millican, K. H. Muller, A. M. Sharkey, and S. K. Smith. Vascular endothelial growth factor is produced by peritoneal fluid macrophages in endometriosis and is regulated by ovarian steroids. J. Clin. Invest. 98:482-489 (1996). doi:10.1172/JCI118815.

15. A. Del Maschio, A. Zanetti, M. Corada, Y. Rival, L. Ruco, M. G. Lampugnani, and E. Dejana. Polymorphonuclear leukocyte adhesion triggers the disorganization of endothelial cell-to-cell adherens junctions. J. Cell. Biol. 135:497-510 (1996). doi:10.1083/ jcb.135.2.497.

16. A. M. Joussen, V. Poulaki, W. Qin, B. Kirchhof, N. Mitsiades, S. J. Wiegand, J. Rudge, G. D. Yancopoulos, and A. P. Adamis. Retinal vascular endothelial growth factor induces intercellular adhesion molecule-1 and endothelial nitric oxide synthase expression and initiates early diabetic retinal leukocyte adhesion in vivo. Am. J. Pathol. 160:501-509 (2002)

17. D. A. Antonetti, E. B. Wolpert, L. DeMaio, N. S. Harhaj, and R. C. Scaduto Jr. Hydrocortisone decreases retinal endothelial cell water and solute flux coincident with increased content and decreased phosphorylation of occludin. J. Neurochem. 80:667677 (2002). doi:10.1046/j.0022-3042.2001.00740.x.

18. A. Wenzel, C. Grimm, M. W. Seeliger, G. Jaissle, F. Hafezi, R. Kretschmer, E. Zrenner, and C. E. Reme. Prevention of photoreceptor apoptosis by activation of the glucocorticoid receptor. Invest. Ophthalmol. Vis. Sci. 42:1653-1659 (2001).

19. F. Ali. A review of diabetic macular edema. Digit. J. Ophthalmol. (2002).

20. R. Herrero-Vanrell, and M. F. Refojo. Biodegradable microspheres for vitreoretinal drug delivery. Adv. Drug Deliv. Rev. 52:516 (2001). doi:10.1016/S0169-409X(01)00200-9.

21. J. V. Aukunuru, G. Sunkara, N. Bandi, W. B. Thoreson, and U. B. Kompella. Expression of multidrug resistance-associated protein (MRP) in human retinal pigment epithelial cells and its interaction with BAPSG, a novel aldose reductase inhibitor. Pharm. Res. 18:565-572 (2001). doi:10.1023/A:1011 060705599.
22. N. J. Mangini, and B. G. Kennedy. Native and cultured human RPE express P-glycoprotein, ARVO Annual Meeting, 2002.

23. P. M. Hughes, O. Olejnik, J. E. Chang-Lin, and C. G. Wilson. Topical and systemic drug delivery to the posterior segments. Adv. Drug Deliv. Rev. 57:2010-2032 (2005). doi:10.1016/j.addr. 2005.09.004.

24. V. H. L. Lee, K. J. Pince, D. A. Frambach, and B. T. Martini. Drug delivery to the posterior segment. Oxford University Press, New York, 1998.

25. P. Quiroga, A. Dominquez, and M. Jareno. El tratamento de enfermedads medicas con triamcinolone intravitrea. Arch. Doc. Esp. Oftalmol. 65:491-498 (1993).

26. M. Bessler, B. W. McCuen, and Y. Tano. The lack of toxicity of intravitreally administered triamcinolone acetonide. Am. J. Ophthalmol. 91:785-788 (1981).

27. H. S. Chin, T. S. Park, Y. S. Moon, and J. H. Oh. Difference in clearance of intravitreal triamcinolone acetonide between vitrectomized and nonvitrectomized eyes. Retina 25:556-560 (2005). doi:10.1097/00006982-200507000-00002.

28. C. M. Jermak, J. T. Dellacroce, J. Heffez, and G. A. Peyman. Triamcinolone acetonide in ocular therapeutics. Surv. Ophthalmol. 52:503-522 (2007). doi:10.1016/j.survophthal.2007.06.004.

29. M. A. Cunningham, J. L. Edelman, and S. Kaushal. Intravitreal steroids for macular edema: the past, the present, and the future. Surv. Ophthalmol. 53:139-149 (2008). doi:10.1016/j. survopht hal.2007.12.005.

30. R. Klein, B. E. Klein, S. E. Moss, M. D. Davis, and D. L. DeMets The Wisconsin epidemiologic study of diabetic retinopathy. IV. Diabetic macular edema. Ophthalmology. 91:1464-1474 (1984).

31. C. H. Meyer. Current treatment approaches in diabetic macular edema. Ophthalmologica. 221:118-131 (2007). doi:10.1159/ 000098257.

32. F. Bandello, R. Pognuz, A. Polito, A. Pirracchio, F. Menchini, and M. Ambesi. Diabetic macular edema: classification, medical and laser therapy. Semin. Ophthalmol. 18:251-258 (2003). doi:10.1080/08820530390895262.

33. B. Sander. Diabetic macular edema evaluated by optical coherence tomography. Acta. Ophthalmol. Scand. 84:90 (2006). doi:10.1111/j.1600-0420.2006.00712_39.x.

34. M. Colucciello. Intravitreal bevacizumab and triamcinolone acetonide combination therapy for exudative neovascular agerelated macular degeneration: short-term optical coherence tomography results. J. Ocul. Pharmacol. Ther. 24:15-24 (2008). doi:10.1089/jop.2007.0080

35. J. A. Tielsch. Vision problems in the US: a report on blindness and vision impairment in adults age 40 and older, Prevent Blindness America. Schaumburg, IL: Prevent Blindness, 1994.

36. P. H. O. Olejnik. Drug delivery strategies to treat age-related macular degeneration. Adv. Drug Deliv. Rev. 57:1991-1993 (2005). doi:10.1016/j.addr.2005.09.002.

37. L. P. Iu, and A. K. Kwok. An update of treatment options for neovascular age-related macular degeneration. Hong Kong Med. J. 13:460-470 (2007).

38. J. S. Sunness, G. S. Rubin, C. A. Applegate, N. M. Bressler, M. J. Marsh, B. S. Hawkins, and D. Haselwood. Visual function abnormalities and prognosis in eyes with age-related geographic atrophy of the macula and good visual acuity. Ophthalmology 104:1677-1691 (1997)

39. C. N. Singh, and D. A. Saperstein. Combination treatment with reduced-fluence photodynamic therapy and intravitreal injection of triamcinolone for subfoveal choroidal neovascularization in macular degeneration. Retina 28:789-793 (2008). doi:10.1097/ IAE.0b013e31817082d7.

40. A. Frimpong-Boateng, A. Bunse, F. Rufer, and J. Roider Photodynamic therapy with intravitreal application of triamcinolone acetonide in age-related macular degeneration: functional results in 54 patients. Acta Ophthalmol. 1-5 (2008).

41. G. Weigert, S. Michels, S. Sacu, A. Varga, F. Prager, W. Geitzenauer, and U. Schmidt-Erfurth. Intravitreal bevacizumab (Avastin) therapy versus photodynamic therapy plus intravitreal triamcinolone for neovascular age-related macular degeneration: 6-month results of a prospective, randomised, controlled clinical study. Br. J. Ophthalmol. 92:356-360 (2008). doi:10.1136/bjo.2007.125823. 
42. J. Bradley, M. Ju, and G. S. Robinson. Combination therapy for the treatment of ocular neovascularization. Angiogenesis 10:141-148 (2007). doi:10.1007/s10456-007-9069-x.

43. U. M. Schmidt-Erfurth, and C. Pruente. Management of neovascular age-related macular degeneration. Prog. Retin. Eye Res. 26:437-451 (2007). doi:10.1016/j.preteyeres.2007.03.002.

44. U. M. Schmidt-Erfurth, G. Richard, A. Augustin, W. G. Aylward, F. Bandello, B. Corcostegui, J. Cunha-Vaz, A. Gaudric, A. Leys, and R. O. Schlingemann. Guidance for the treatment of neovascular age-related macular degeneration. Acta. Ophthalmol. Scand. 85:486-494 (2007). doi:10.1111/j.1755-3768.2007.00979.x.

45. U. Schmidt-Erfurth, M. Niemeyer, W. Geitzenauer, and S. Michels. Time course and morphology of vascular effects associated with photodynamic therapy. Ophthalmology 112:2061-2069 (2005). doi:10.1016/j.ophtha.2005.09.007.

46. U. Schmidt-Erfurth, U. Schlotzer-Schrehard, C. Cursiefen, S. Michels, A. Beckendorf, and G. O. Naumann. Influence of photodynamic therapy on expression of vascular endothelial growth factor (VEGF), VEGF receptor 3, and pigment epithelium-derived factor. Invest. Ophthalmol. Vis. Sci. 44:4473-4480 (2003). doi:10.1167/iovs.02-1115.

47. M. C. Gillies, J. M. Simpson, W. Luo, P. Penfold, A. B. Hunyor, W. Chua, P. Mitchell, and F. Billson. A randomized clinical trial of a single dose of intravitreal triamcinolone acetonide for neovascular age-related macular degeneration: one-year results. Arch. Ophthalmol. 121:667-673 (2003). doi:10.1001/archopht.121.5.667.

48. C. Durairaj, J. C. Shah, S. Senapati, and U. B. Kompella. Prediction of vitreal half-life based on drug physicochemical properties: quantitative structure-pharmacokinetic relationships (QSPKR). Pharm Res (2008). doi:10.1007/s11095-008-9728-7.

49. H. Kim, K. G. Csaky, L. Gravlin, P. Yuan, R. J. Lutz, P. M. Bungay, G. Tansey, D. E. F. Monasterio, G. K. Potti, G. Grimes, and M. R. Robinson. Safety and pharmacokinetics of a preservative-free triamcinolone acetonide formulation for intravitreal administration. Retina 26:523-530 (2006). doi:10.1097/ 00006982-200605000-00005.

50. B. C. Gilger, E. Malok, T. Stewart, P. Ashton, T. Smith, G. J. Jaffe, and J. B. Allen. Long-term effect on the equine eye of an intravitreal device used for sustained release of cyclosporine A. Vet. Ophthalmol. 3:105-110 (2000). doi:10.1046/j.14635224.2000.00117.x.

51. B. D. Kuppermann. Implants can deliver corticosteroids, pharmacologic agents, Retina Today, 2007, pp. 27-31.

52. B. D. Kuppermann, M. S. Blumenkranz, J. A. Haller, G. A Williams, D. V. Weinberg, C. Chou, and S. M. Whitcup. Randomized controlled study of an intravitreous dexamethasone drug delivery system in patients with persistent macular edema. Arch. Ophthalmol. 125:309-317 (2007). doi:10.1001/ archopht.125.3.309.

53. S. K. Seah, R. Husain, G. Gazzard, M. C. Lim, S. T. Hoh, F. T. Oen, and T. Aung. Use of surodex in phacotrabeculectomy surgery. Am. J. Ophthalmol. 139:927-928 (2005). doi:10.1016/j. ajo.2004.10.052.

54. A. C. Wadood, A. M. Armbrecht, P. A. Aspinall, and B. Dhillon. Safety and efficacy of a dexamethasone anterior segment drug delivery system in patients after phacoemulsification. J. Cataract. Refract. Surg. 30:761-768 (2004). doi:10.1016/j. jcrs.2003.08.028.

55. G. J. Jaffe, D. Martin, D. Callanan, P. A. Pearson, B. Levy, and T. Comstock. Fluocinolone acetonide implant (Retisert) for noninfectious posterior uveitis: thirty-four-week results of a multicenter randomized clinical study. Ophthalmology 113:1020-1027 (2006). doi:10.1016/j.ophtha.2006.02.021.

56. J. L. Bourges, C. Bloquel, A. Thomas, F. Froussart, A. Bochot, F. Azan, R. Gurny, D. BenEzra, and F. Behar-Cohen. Intraocular implants for extended drug delivery: therapeutic applications. Adv. Drug. Deliv. Rev. 58:1182-1202 (2006). doi:10.1016/j.addr.2006.07.026.

57. P. A. Sieving, R. C. Caruso, W. Tao, H. R. Coleman, D. J. Thompson, K. R. Fullmer, and R. A. Bush. Ciliary neurotrophic factor (CNTF) for human retinal degeneration: phase I trial of CNTF delivered by encapsulated cell intraocular implants. Proc. Natl. Acad. Sci. U. S. A. 103:3896-3901 (2006). doi:10.1073/pnas.0600236103.
58. W. Tao. Application of encapsulated cell technology for retinal degenerative diseases. Expert Opin. Biol. Ther. 6:717-726 (2006). doi:10.1517/14712598.6.7.717.

59. J. I. Lim, R. A. Wolitz, A. H. Dowling, H. R. Bloom, A. R. Irvine, and D. M. Schwartz. Visual and anatomic outcomes associated with posterior segment complications after ganciclovir implant procedures in patients with AIDS and cytomegalovirus retinitis. Am. J. Ophthalmol. 127:288-293 (1999). doi:10.1016/S0002-9394(98)00443-7.

60. T. Yasukawa, Y. Ogura, Y. Tabata, H. Kimura, P. Wiedemann, and Y. Honda. Drug delivery systems for vitreoretinal diseases. Prog. Retin. Eye Res. 23:253-281 (2004). doi:10.1016/j. preteyeres.2004.02.003.

61. T. Yasukawa, Y. Ogura, E. Sakurai, Y. Tabata, and H. Kimura. Intraocular sustained drug delivery using implantable polymeric devices. Adv. Drug Deliv. Rev. 57:2033-2046 (2005). doi:10.1016/j. addr.2005.09.005.

62. T. J. Smith, P. A. Pearson, D. L. Blandford, J. D. Brown, K. A. Goins, J. L. Hollins, E. T. Schmeisser, P. Glavinos, L. B. Baldwin, and P. Ashton. Intravitreal sustained-release ganciclovir. Arch. Ophthalmol. 110:255-258 (1992).

63. J. Y. Driot, G. D. Novack, K. D. Rittenhouse, C. Milazzo, and P. A. Pearson. Ocular pharmacokinetics of fluocinolone acetonide after Retisert intravitreal implantation in rabbits over a 1-year period. J. Ocul. Pharmacol. Ther. 20:269-275 (2004). doi:10.1089/ 1080768041223611.

64. T. A. Ciulla, M. H. Criswell, R. P. Danis, M. Fronheiser, P. Yuan, T. A. Cox, K. G. Csaky, and M. R. Robinson. Choroidal neovascular membrane inhibition in a laser treated rat model with intraocular sustained release triamcinolone acetonide microimplants. Br. J. Ophthalmol. 87:1032-1037 (2003). doi:10.1136/bjo.87.8.1032.

65. N. R. Beeley, J. M. Stewart, R. Tano, L. R. Lawin, R. A Chappa, G. Qiu, A. B. Anderson, E. de Juan, and S. E. Varner. Development, implantation, in vivo elution, and retrieval of a biocompatible, sustained release subretinal drug delivery system. J. Biomed. Mater. Res. A. 76:690-698 (2006). doi:10.1002/ jbm.a.30567.

66. S. Varner. Coatings: sustained-release drug delivery for retinal disease, MDDI Archive, 2005.

67. B. A. Booth, L. Vidal Denham, S. Bouhanik, J. T. Jacob, and J. M. Hill. Sustained-release ophthalmic drug delivery systems for treatment of macular disorders: present and future applications. Drugs Aging 24:581-602 (2007). doi:10.2165/00002512-20072407000006 .

68. N. R. Beeley, J. V. Rossi, P. A. Mello-Filho, M. I. Mahmoud, G. Y. Fujii, E. de Juan Jr., and S. E. Varner. Fabrication, implantation, elution, and retrieval of a steroid-loaded polycaprolactone subretinal implant. J. Biomed. Mater. Res. A 73:437-444 (2005). doi:10.1002/jbm.a.30294.

69. T. Zhou, H. Lewis, R. E. Foster, and S. P. Schwendeman. Development of a multiple-drug delivery implant for intraocular management of proliferative vitreoretinopathy. J. Control. Release 55:281-295 (1998). doi:10.1016/S0168-3659(98)00061-3.

70. D. D. Lewis. Controlled release of bioactive agents from lactide/glycolide polymers. In: M. Chasin and R. Langer (eds.), Biodegradable Polymers as Drug Delivery Systems, Biodegradable Polymers as Drug Delivery Systems, Marcel Dekker, New York, 1990.

71. L. J. Suggs, and A. G. Mikos. Synthetic biodegradable polymers for medical applications. In E. Mark (ed.), Physical Properties of Polymers, American Institute of Physics, Woodbury, NY, 1996, pp. 615-624.

72. A. A. Hincal, and S. Calis. Microsphere preparation by solvent evaporation method. In D. L. Wise (ed.), Handbook of Pharmaceutical Controlled Release Technology, Marcel Dekker, New York, 2000, pp. 329-343.

73. O. Felt-Baeyens, S. Eperon, P. Mora, D. Limal, S. Sagodira, P. Breton, B. Simonazzi, L. Bossy-Nobs, Y. Guex-Crosier, and R. Gurny. Biodegradable scleral implants as new triamcinolone acetonide delivery systems. Int. J. Pharm. 322:6-12 (2006). doi:10.1016/j.ijpharm.2006.05.053.

74. P. Breton, D. Roy, L. Marchal-Heussler, C. Seguin, P. Couvreur, and F. Lescure. New poly(methylidene malonate 2. 1. 2.). In G. 
Gregoriadis (ed.), Nanoparticles: Recent Developments, Vol. 4, Plenum, New York, 1994, pp. 161-172.

75. F. Lescure, C. Seguin, P. Breton, P. Bourrinet, D. Roy, and P. Couvreur. Preparation and characterization of novel poly (methylidene malonate 2.1.2.)-made nanoparticles. Pharm. Res. 11:1270-1277 (1994). doi:10.1023/A:1018986226557.

76. S. Eperon, L. Bossy-Nobs, I. K. Petropoulos, R. Gurny, and Y. Guex-Crosier. A biodegradable drug delivery system for the treatment of postoperative inflammation. Int. J. Pharm. 352:240-247 (2008).

77. D. T. Tan, S. P. Chee, L. Lim, and A. S. Lim. Randomized clinical trial of a new dexamethasone delivery system (Surodex) for treatment of post-cataract surgery inflammation. Ophthalmology 106:223-231 (1999). doi:10.1016/S0161-6420(99)90060$\mathrm{X}$.

78. A. S. Berger, C. K. Cheng, P. A. Pearson, P. Ashton, P. A. Crooks, T. Cynkowski, G. Cynkowska, and G. J. Jaffe. Intravitreal sustained release corticosteroid-5-fluoruracil conjugate in the treatment of experimental proliferative vitreoretinopathy. Invest. Ophthalmol. Vis. Sci. 37:23182325 (1996).

79. T. A. Macky, C. Oelkers, U. Rix, M. L. Heredia, E. Kunzel, M. Wimberly, B. Rohrer, C. E. Crosson, and J. Rohr. Synthesis, pharmacokinetics, efficacy, and rat retinal toxicity of a novel mitomycin C-triamcinolone acetonide conjugate. J. Med. Chem. 45:1122-1127 (2002). doi:10.1021/jm010511b.

80. C. S. Yang, J. A. Khawly, D. P. Hainsworth, S. N. Chen, P. Ashton, H. Guo, and G. J. Jaffe. An intravitreal sustainedrelease triamcinolone and 5-fluorouracil codrug in the treatment of experimental proliferative vitreoretinopathy. Arch. Ophthalmol. 116:69-77 (1998).

81. U. B. Kompella, N. Bandi, and S. P. Ayalasomayajula. Subconjunctival nano- and microparticles sustain retinal delivery of budesonide, a corticosteroid capable of inhibiting VEGF expression. Invest. Ophthalmol. Vis. Sci. 44:1192-201 (2003). doi:10.1167/iovs.02-0791.

82. B. Khoobehi, M. O. Stradtmann, G. A. Peyman, and O. M. Aly. Clearance of sodium fluorescein incorporated into microspheres from the vitreous after intravitreal injection. Ophthalmic. Surg. 22:175-180 (1991).

83. T. Moritera, Y. Ogura, N. Yoshimura, Y. Honda, R. Wada, S. H. Hyon, and Y. Ikada. Biodegradable microspheres containing adriamycin in the treatment of proliferative vitreoretinopathy. Invest. Ophthalmol. Vis. Sci. 33:3125-3130 (1992).

84. R. Herrero-Vanrell, L. Ramirez, A. Fernandez-Carballido, and M. F. Refojo. . Biodegradable PLGA microspheres loaded with ganciclovir for intraocular administration. Encapsulation technique, in vitro release profiles, and sterilization process. Pharm. Res. 17:1323-1328 (2000). doi:10.1023/A:1026464124412.

85. H. Kimura, Y. Ogura, T. Moritera, Y. Honda, Y. Tabata, and Y. Ikada. In vitro phagocytosis of polylactide microspheres by retinal pigment epithelial cells and intracellular drug release. Curr. Eye Res. 13:353-360 (1994).

86. T. Moritera, Y. Ogura, N. Yoshimura, S. Kuriyama, Y. Honda, Y. Tabata, and Y. Ikada. Feasibility of drug targeting to the retinal pigment epithelium with biodegradable microspheres. Curr. Eye Res. 13:171-176 (1994). doi:10.3109/02713689408995774.

87. Y. Ogura, and H. Kimura. Biodegradable polymer microspheres for targeted drug delivery to the retinal pigment epithelium. Surv. Ophthalmol. 39(Suppl 1):S17-24 (1995). doi:10.1016/S0039-6257(05)80069-4.

88. A. A. Veloso Jr., Q. Zhu, R. Herrero-Vanrell, and M. F. Refojo. Ganciclovir-loaded polymer microspheres in rabbit eyes inoculated with human cytomegalovirus. Invest. Ophthalmol. Vis. Sci. 38:665-675 (1997).

89. T. Moritera, Y. Ogura, Y. Honda, R. Wada, S. H. Hyon, and Y. Ikada. Microspheres of biodegradable polymers as a drugdelivery system in the vitreous. Invest. Ophthalmol. Vis. Sci. 32:1785-1790 (1991).

90. J. A. Cardillo, A. A. Souza-Filho, and A. G. Oliveira. Intravitreal Bioerudivel sustained-release triamcinolone microspheres system (RETAAC). Preliminary report of its potential usefulness for the treatment of diabetic macular edema. Arch. Soc. Esp. Oftalmol. 81:675-677 (2006). 679-681.
91. D. F. Martin, D. J. Parks, and S. D. Mellow. Treatment of cytomegalovirus retinitis with an intraocular sustained-release ganciclovir implant: a randomized controlled clinical trial. Arch. Ophthalmol. 112:1531-1539 (1994).

92. G. J. Jaffe, R. M. McCallum, B. Branchaud, C. Skalak, Z. Butuner, and P. Ashton. Long-term follow-up results of a pilot trial of a fluocinolone acetonide implant to treat posterior uveitis. Ophthalmology 112:1192-1198 (2005). doi:10.1016/j. ophtha.2005.03.013.

93. G. J. Jaffe, C. H. Yang, H. Guo, J. P. Denny, C. Lima, and P. Ashton. Safety and pharmacokinetics of an intraocular fluocinolone acetonide sustained delivery device. Invest Ophthalmol. Vis. Sci. 41:3569-3575 (2000)

94. D. F. Martin, F. L. Ferris, D. J. Parks, R. C. Walton, S. D. Mellow, D. Gibbs, N. A. Remaley, P. Ashton, M. D. Davis, C. C. Chan, and R. B. Nussenblatt. Ganciclovir implant exchange. Timing, surgical procedure, and complications. Arch. Ophthalmol. 115:1389-1394 (1997).

95. T. W. Olsen, X. Feng, K. Wabner, S. R. Conston, D. H. Sierra, D. V. Folden, M. E. Smith, and J. D. Cameron. Cannulation of the suprachoroidal space: a novel drug delivery methodology to the posterior segment. Am. J. Ophthalmol. 142:777-787 (2006). doi:10.1016/j.ajo.2006.05.045

96. L. D. Pizzarello, F. A. Jakobiec, A. J. Hofeldt, M. M. Podolsky, and D. N. Silvers. Intralesional corticosteroid therapy of chalazia. Am. J. Ophthalmol. 85:818-821 (1978).

97. E. Zamir, R. W. Read, R. E. Smith, R. C. Wang, and N. A. Rao. A prospective evaluation of subconjunctival injection of triamcinolone acetonide for resistant anterior scleritis. Ophthalmology 109:798-805 (2002). discussion 805-7.

98. A. A. Okada, T. Wakabayashi, Y. Morimura, S. Kawahara, E. Kojima, Y. Asano, and T. Hida. Trans-Tenon's retrobulbar triamcinolone infusion for the treatment of uveitis. $\mathrm{Br}$. J. Ophthalmol. 87:968-971 (2003). doi:10.1136/bjo.87.8.968.

99. S. Singh, V. Pal, and C. S. Dhull. Supratarsal injection of corticosteroids in the treatment of refractory vernal keratoconjunctivitis. Ind. J. Ophthalmol. 50:160-161 (2001).

100. R. Ebner, M. H. Devoto, D. Weil, M. Bordaberry, C. Mir, H. Martinez, L. Bonelli, and H. Niepomniszcze. Treatment of thyroid associated ophthalmopathy with periocular injections of triamcinolone. Br. J. Ophthalmol. 88:1380-1386 (2004). doi:10.1136/bjo.2004.046193.

101. N. Benhamou, P. Massin, B. Haouchine, F. Audren, R. Tadayoni, and A. Gaudric. Intravitreal triamcinolone for refractory pseudophakic macular edema. Am. J. Ophthalmol. 135:246-249 (2003). doi:10.1016/S0002-9394(02)01938-4.

102. F. Audren, A. Erginay, B. Haouchine, R. Benosman, J. Conrath, J. F. Bergmann, A. Gaudric, and P. Massin. Intravitreal triamcinolone acetonide for diffuse diabetic macular oedema: 6-month results of a prospective controlled trial. Acta. Ophthalmol. Scand. 84:624-630 (2006). doi:10.1111/j.16000420.2006.00700.x.

103. Z. F. Bashshur, R. N. Ma'luf, S. Allam, F. A. Jurdi, R. S Haddad, and B. N. Noureddin. Intravitreal triamcinolone for the management of macular edema due to nonischemic central retinal vein occlusion. Arch. Ophthalmol. 122:1137-1140 (2004). doi:10.1001/archopht.122.8.1137.

104. M. S. Ip, J. L. Gottlieb, A. Kahana, I. U. Scott, M. M. Altaweel, B. A. Blodi, R. E. Gangnon, and C. A. Puliafito. Intravitreal triamcinolone for the treatment of macular edema associated with central retinal vein occlusion. Arch. Ophthalmol. 122:11311136 (2004). doi:10.1001/archopht.122.8.1131.

105. R. P. Danis, T. A. Ciulla, L. M. Pratt, and W. Anliker. Intravitreal triamcinolone acetonide in exudative age-related macular degeneration. Retina 20:244-50 (2000). doi:10.1097/ 00006982-200005000-00003.

106. L. M. Smithen, and R. F. Spaide. Photodynamic therapy and intravitreal triamcinolone for a subretinal neovascularization in bilateral idiopathic juxtafoveal telangiectasis. Am. J. Ophthalmol. 138:884-885 (2004). doi:10.1016/j.ajo.2004.05.073.

107. E. Rechtman, V. D. Allen, R. P. Danis, L. M. Pratt, A. Harris, and M. A. Speicher. Intravitreal triamcinolone for choroidal neovascularization in ocular histoplasmosis syndrome. Am. J. Oph thalmol. 136:739-741 (2003). doi:10.1016/S0002-9394(03)00389-1. 
108. R. E. Andrade, C. Muccioli, M. E. Farah, R. B. Nussenblatt, and R. Belfort Jr. Intravitreal triamcinolone in the treatment of serous retinal detachment in Vogt-Koyanagi-Harada syndrome. Am. J. Ophthalmol. 137:572-574 (2004). doi:10.1016/j.ajo.2003.08.035.

109. C. Furino, T. Micelli Ferrari, F. Boscia, N. Cardascia, N. Recchimurzo, and C. Sborgia. Triamcinolone-assisted pars plana vitrectomy for proliferative vitreoretinopathy. Retina 23:771-776 (2003). doi:10.1097/00006982-200312000-00004.

110. S. E. Burk, A. P. Da Mata, M. E. Snyder, S. Schneider, R. H. Osher, and R. J. Cionni. Visualizing vitreous using Kenalog suspension. J. Cataract. Refract. Surg. 29:645-651 (2003). doi:10.1016/S0886-3350(03)00016-6. 